\section{RESEARCH WORK IN INSANITY AND THE STUDY OF CURATIVE TREATMENT OF THE INSANE. ${ }^{1}$}

By H. Oswald Smith, M.B., Ch.B. Edin.,

MEMBER OF THF STANDING LUNACY COMMITTEC OF THE SURREY COUNTY COUNCIL; MEMBER OF THE NETHERNE VISTING DEFICLENCY COMMITTEES.

\section{A Report to Establish and Organise a Research Laboratory} at Netherne Asylum.

THIs report is based on methods adopted by several of the large asylums, at the heads of which are medical men who have advanced psychiatry to a much more hopeful position, and whose efforts are still being maintained along these channels of research whereby new methods of treatment are evolved for the benefit of the mentally afficted.

An asylum ought not to be merely a place where patients are well cared for and housed, but must have a definite plan so that research work is undertaken by a specially appointed officer who is enthusiastic about his work and efficient in the present-day technique of research work in psychiatry. $\mathrm{He}$ should have the proper facilities in a well-equipped laboratory for laboratory diagnosis and study. There must, however, be cooperation between this officer and the resident staff in the work. The primary duty of the resident staff is -(1) the proper examination, (2) treatment, and (3) care of the patients. This work provides infinite lines for study and research for the medical staff, provided always that their primary duties do not take up their whole time. It is well known that certain men who are interested in research work will make time for such extra duties; thus they keep abreast of medical progress and form their own judgment as to the permanent value of the latest advances and ideas.

There are many lines of a clinical and therapeutical nature that can be most appropriately followed out by the ordinary staff. At the same time it is of the greatest advantage to county asylums, such as Netherne, that a fairly equipped laboratory should be regarded as essential. If the ordinary medical staff find that their time is so fully taken up with the ordinary work in the wards that they have not time or that they have not the necessary technical training to do laboratory work -as to the amount of medical work in an asylum the annual admission rate gives a fair indication of the amount of work to be undertaken-a pathologist should be provided at a salary of not less than $£ 250$ a year to begin with, in order to get a really good and efficient man, because the ultimate research work would rest largely in his hands. If the assistant medical officers have time to follow up a clinical and therapeutical research, then such an appointment would bear good results, but if the medical staff have not the necessary time, then instead of a pathologist the appointment of a laboratory physician might be made at an initial salary of $£ 250$ a year.

This physiciar could have the laboratory fitted up according to his special requirements, and such sum as $£ 250$ as a preliminary outlay would be sufficient. It is only after years of time, thought, and expenditure of money that curative research has reached the high-water mark obtained in such asylums as the Lancashire County Asylum at Prestwich, the Crichton Royal Institution, and the Edinburgh Royal Asylum. The knowledge of curative research is added to slowly, but if such a scheme as the above is adopted at Netherne the com. mittee will have the benefit of the research work of these asylums and the practical results. When Netherne earns such a report from the Commissioners in Lunacy as the Crichton Royal Institution did for 1912, then, and not till then, shall we be able to say that the patients at Netherne are receiving the most appropriate treatment. If the total expenditure on research work be divided by the average amount of patients under treatment a year it will be found that the general cost per caput per annum for the purposes of laboratory diagnosis, study, and research is not a fraction

1 Being a report to establish and organise a research laboratory at Netherne Asylum, with remarks upon the open-air treatment of the insane and organic therapy treatment. The report was adopted by the Standing Lunacy Committee of the Surrey county council on July 7 th, Stzndin. of the cost of each patient's keep, and such expenditure would be well worth it.

Estimate (apart from cost of building) of initial expenditure for the purpose of promoting eurative research work at Netherne.

Pathologist at a salary of $£ 250$ a year, with residence; or at a salary of $£ 300$ a year living outside.

A further sum of $£ 250$ for initial expenditure in fitting up a laboratory.

The above scheme presupposes the cooperation of the resident medica staff along the lines of clinical and therapeutical treatment.

Failing this cooperation in the mean while the appointment of a-

Laboratory physician at an initial salary of $\$ 250$ a year, with residence; or $\$ 300$ a year outside.

A sum or $£ 250$ for initial expenditure in fitting up a laboratory.

Forms of application for the above post, whichever is decided upon, can be subsequently drawn up so as to get the best candidates.

\section{Organotherapy.}

The second part of this report deals with organotherapy and the open-air treatment of the active insane by rest in bed. The committee must look to the resident medical staff to carry out this part of the work. In psychiatry and neurology great advances have been made, and these are due to the whole-hearted efforts of men who have ever kept the flag of research flying. There opens out the vista of organotherapy, and by this is meant the employment of certain glandular extracts in the treatment of insanity. Thyroid extract, cerebral extract, mammary, pancreatic, ovarian, pituitary and orchitic extracts, these are some which have been used and experimented with by psychiatrists. It is known that causes of cretinism can be combated by the use of thyroid, and Brown-Séquard maintained that he had "rejuvenated" himself by orchitic extract. Myxœdema, due to the absence of the thyroid gland, can be cured by the administration of thyroid extract. Cerebral extract is found to promote the appetite, and is a good tonic to the general nervous system. These are some examples of the research work placed at the disposal of humanity and obtained by means of work in the laboratory. The committee should expect coöperative research to be based on these lines, which should also embrace the bacteriological examination of the blood and cerebro-spinal fluid, the conditions of which have an important bearing on general paralysis of the insane. The use of vaccines and antisera would have to be investigated.

Administrative duties have become so heavy that it is impossible in many cases for the medical superintendent to give much attention to clinical work, and so we must expect the assistant medical officers who have adopted lunacy service as a specialty to be properly trained in up-to-date knowledge of the treatment of the insane. Post-graduate courses are provided in connexion with most of the universities.

Open-air Treatment by Rest in Bed.

And finally there must be placed on record an estimate of a form of treatment of the insane from which there is expected brilliant results. It is the open-air treatment of the active insane by rest in bed. This treatment can be carried out by the staff without undue strain on their time and little additional expenditure of money. It has been carried out with great success at Ayr Asylum with a resulting increase in the recovery rate. Verandahs are used on the male and female sides. Separate beds with wooden partitions are placed on these verandahs. (Details of the scheme can be supplied.)

What are the effects of rest in bed in the open air in the case of newly admitted and actively insane patients, and wherein do the effects of outdoor rest in bed differ from those of outdoor exercise and indoor rest? First and foremost, there is a rapid subsidence of the active mental and nervous symptoms, there is a rapid amelioration of mania, melancholia, delirium, vivid hallucinatory and delusional manifestations, of restlessness and excitement of all kinds and insomnia. The general effect is that the large majority of newly admitted patients show distinct improvement of various morbid mental states, become less restless, more manageable, and more contented, and regain their sleep with greater rapidity than with any other known method. Secondly, there is a rapid improvement in the physical condition, a noticeable improvement in the condition of the skin, the appetite improves, and the majority readily take their food and do not require to be spoon-fed as is usual with new patients ; a distinct improvement in the state of the tongue and gastric digestion if previously impaired. Hypnotics, sedatives, and laxatives can under this treatment be dispensed with. The increase in the body weight is $5 \mathrm{lb}$., 6lb., or $7 \mathrm{lb}$. during the first two or 
three weeks on simple diet, consisting largely of milk and milk-puddings.

Similar treatment can be adopted in the cases of all residents of shorter or longer standing, exhibiting relapses or phases of active insanity, including the most difficult and dangerous cases in the asylum. The wooden partitions already alluded to add the valuable feature of isolation to the treatment. The recovery rate is remarkably influenced by this treatment. From the description of the open-air treatment of the insane it will be at once seen that the combination of rest in bed with open-air treatment secures the natural rest to the nervous system and gives the patients in their initial treatment a good chance of recovery; the cost in mere money would be very little in comparison to the benefits. It is a pleasant remedy, both to those who receive the treatment and those who administer it. In placing these points before you, I wish to acknowledge the assistance I have received from many of the leading psychiatrists, who have willingly placed their knowledge at my disposal for the benefit of the committee. I have had the privilege of reading many of the special papers published in the medical journals. The length of the report is owing to the difficulties of the subject which has been too inadequately handled by me.

\section{The Recovery Rate and the Cost of the schemes.}

The recovery rate for 1912 on all admissions into the Crichton Royal Institute was 35.5 per cent. ; the Edinburgh Royal Asylum 36.0 per cent. In both these institutions research work is diligently carried on. The recovery rate on all admissions into Netherne Asylum for 1909 to 1912 was 12.0 per cent ; Brookwood Asylum for $45 \frac{1}{2}$ years, 24.6 per cent. In future the annual recovery rate should be placed on record, so that a just and fair comparative result may be available.

It is therefore necessary to deal with curative research at Netherne Asylum from the practical point of view so far as cost is concerned. Dr. S. N. Crowther, senior medical officer of Netherne, has worked out the cost of a scheme which includes buildings, fittings, salaries, and upkeep. This scheme embraces the cost of open-air treatment of the insane by rest in bed and the proper grading of the insane.

Summary of annual cost per head per week:-(1) Curative research, $2.51 d$.; (2) open-air treatment, $1 \cdot 35 d$.: (3) grading of patients, $4.03 d$. -total cost of three schemes, $7.89 d$. This includes salary of a pathologist and neurologist at $£ 350$ per annum.

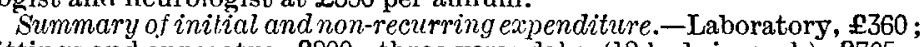
fittings and apparatus, $£ 200$; three verandahs (12 beds in each), $\$ 765$ total cost of the three schemes, $£ 1325$.

\section{The Grading of Patients.}

The attention to the proper grading of patients in all asylums is called for. Asylum patients may be divided into two main classes-(1) curable and (2) incurable; and while for those of the first class every means known to science should be used to facilitate recovery, the treatment of the second class is not so important, and the present method of grading is on the whole satisfactory. It is mainly the extra cost which has hitherto deterred the asylum authorities from proper grading of patients. It was usual to distribute a certain number of noisy and excited patients among those who were miserable and depressed, with the hope that an interaction might take place to the mutual benefit of the patients concerned. Such methods must be relegated to the background, and it is only by progressive and enlightened treatment, stimulated by research, that psychiatry shall take the long-awaited step forward.

I wish to thank Dr. Crowther for his help and valuable suggestions in the preparation of my paper.

\section{ROYAL ARMY MEDICAL COLLEGE.}

ON Oct. 29th a distribution of prizes by Surgeon-General Sir Havelock Charles, G.C.V.O., took place at the Royal Army Medical College. A large company assembled to do honour to the occasion, among them being Surgeon-Generals W. Donovan. Sir David Bruce, G. J. H. Evatt, H. R. Whitehead, W. H. Macnamara. Sir Francis Trevor, and Sir Charles Cuffe, A. W. May (Director-General of the Medical Department, Royal Navy), Sir James Porter, Sir A. Bradshaw, and many others, including Major Sir Ronald Ross, Lieutenant-Colonel P. J. Freyer, Dr. James Galloway, Mr. A. E. J. Barker, and Dr. F. W. Mott.
Surgeon-General W. BaBTIE, V.C., C.B., C.M.G., Deputy Director-General, opened the proceedings by calling upon the Commandant to read his report.

Colonel BrUCE M. Skinner, M.V.O. (Commandant), reviewed the session, the 106th of the junior class of the College, being also the twenty-third held in London. After referring to the Seventeenth International Congress of Medicine, the Naval and Military Section of which held its meetings at the College, he said there had been some changes in the staff. While regretting the completion of tenure of their appointments, they of the College wished God-speed to Major W. S. Harrison, lately professor of tropical medicine, and to Major J. C. Kennedy, assistant professor of pathology, with the hope that their talents so long devoted to this College might find fields fruitful of discovery awaiting the application of their highly trained energies. On the other hand, they welcomed their successors, Lieutenant-Colonel $O$. L. Robinson in the chair of tropical medicine, and Major S. L. Cummins as assistant professor of pathology. With regard to the class now being closed he reminded those present that they were fully qualified doctors before passing into the College, where they had been instructed in matters relating especially to the preservation of health and physical well-being of the soldier. He had nothing but praise for the young officers who composed this class, for they had been most assiduous and attentive, while those who had gained prizes had done remarkably well, and in two cases brilliantly, for instance, the winner of the Fayrer and the Marshall Webb. medals had gained over 90 per cent. of marks in those competitions. He then read the names of those who had gained prizes, as well as those who came second, as follows:-

1st. The Herbert Prize (highest total of marks) : Lieutenant

R. B. Price, R.A.M.C. . D. D. Rankin, R.A.M.C... 536/700 Hygiene.

1st. Parkes Memorial : Lieutenant R. B. Price, R.A.M.C. _.. 153/200 Proxime accessit: Lieutenant A. K. Sinha, I.M.S. ... $\ldots . \quad 151 / 200$ 2nd. De Chaumont : Lieutenant A. L. Urquhart, R.A.M.C. ... 144/200 Proxime accessit: Lieutenant H. C. D. Rankin, R.A.M.C.... 142/200 Pathology.

1st. Fayrer Prize : Lieutenant S. S. Sokhey, I.M.S. ... $\quad \ldots \quad$... $181 / 200$ Proxime accessit: Lieutenant N. M. Mehta, I.M.S. $\ldots \ldots . .160 / 200$ 2nd. Tulloch Memorial : Lieutenant R. B. Price, R.A.M.C. ... 168/200 Proxime accessit : Lieutenant A. L. Urquhart, R.A.M.C.... 164/200 Surgery. 1st. Montefiore : Lieutenant A. Seddon, I.M.S.
2nd. Montefiore : Lieutenant H. C. D. Rankin, R.A.M.C.... Tropical Medicine. 1st. Ranald Martin Gold Medal: Lieutenant A. K. Sinha, I.M.S. C.......... Administration.

1st. Marshall Webb Prize: Lieutenant H. C. D. Rankin,

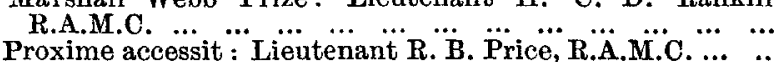

Sir HAVELOCK CHARLES next distributed the prizes with a few appropriate words to each recipient, and in his address which followed advised and encouraged the young officers as to their course in life, directing his remarks more particularly to those whose careers would lie in India. $\mathrm{He}$ said it was often asked why in life the race was not always to the swift nor the battle to the strong; the reason was that some men had not the tact and judgment to avail themselves of the chance when it offered. 'They failed through lack of character. The greatest of all assets was character. He was present at a similar meeting to this 31 years ago, and though he could not recall that any address was given on that occasion, he remembered that on his way up to town he travelled with Sir Joseph Fayrer, whose advice he asked as to how to get on in India. After looking at him for a few seconds Sir Joseph Fayrer said: "Do what you are told; don't grumble; go where you are ordered." of course, young men going to India would have troubles like everyone else, like the panel doctor as well as the medical man in Harley-street; but they should remember Sir Joseph Fayrer's advice ; and, further, they should strive to prove themselves thoroughly reliable-a most valuable characteristic for every officer. They were going to what he considered the most interesting country in the world. He wished them the best of good luck in the words of the Persian poet who said: "May the sweet waters of contentment spring up where'er you place your feet."

Surgeon-General BABTIE thanked the General Officer 